\title{
Consumption plans for the rest of the night among Australian nightlife patrons
}

\author{
Ashlee Curtis ${ }^{1}$, Kerri Coomber ${ }^{1}$, Nic Droste ${ }^{1}$, Shannon Hyder ${ }^{1}$, Richelle Mayshak ${ }^{1}$, Tina Lam², William Gilmore ${ }^{2}$, \\ Tanya Chikritzhs ${ }^{2}$, and Peter. G. Miller ${ }^{1}$ \\ ${ }^{1}$ School of Psychology, Faculty of Health, Deakin University, Geelong, VIC, Australia \\ ${ }^{2}$ National Drug Research Institute, Faculty of Health Sciences, Curtin University, Bentley, WA, Australia
}

\begin{abstract}
Aims: This study investigates associations between blood alcohol content (BAC), gender, location, time of night, and intention to consume more alcohol, energy drinks, and illicit drugs following a street intercept interview.
\end{abstract}

Design: Interviews were conducted from December 2011 to July 2012.

Setting: Interviews were conducted in nightlife areas of Sydney, Melbourne, Perth, Wollongong, and Geelong, between 8 p.m. to 5 a.m.

Participants: Data from 4,203 participants are utilized in the current paper.

Measures: Participants were asked demographic questions, as well as questions about their intentions for the rest of the night (further alcohol, drug, and energy drink use), and completed a breathalyzer test.

Findings: Over $70 \%$ of the nightlife patrons intended to consume more alcohol, and this was more likely for males, regional patrons, and those with a BAC of over $0.08 \mathrm{~g} / 100 \mathrm{ml}$. Overall, intention to use drugs was consistent across BAC, location, and time of night, though males were significantly more likely than females to intend to consume drugs.

Conclusions: Given the risky behaviors of the most intoxicated group out drinking late at night, interventions that target latenight drinking, high levels of intoxication, and high-risk drinkers are indicated.

\section{Introduction}

Public health efforts aimed at reducing harm related to alcohol and other drugs (AOD) commonly focus on education concerning responsible alcohol consumption guidelines. This not only presumes the desire to drink responsibly will take precedence over other desired outcomes of alcohol consumption, such as social facilitation, confidence, mood management, coping, or desired drunkenness (Martens, Rocha, Martin, \& Serrao, 2008; Measham, 2006; Robertson, Aitken, \& Watkins, 2014), but also that persons who have consumed alcohol or who are intoxicated are able to think rationally and make informed decisions. Previous research exploring consumption intentions has relied on retrospective recall of intentions to drink, get drunk, or engage in other risky behaviors. To date, there has been very little peer-reviewed event-specific research into nightlife attendees' intentions for further AOD use during the same occasion, with existing research focusing largely on alcohol consumption. For example, Bellis et al. (2010) reported that $79 \%$ of their 214 U.K. nightlife patrons intended to consume more alcohol, and $51 \%$ of those who already described themselves as drunk intended to consume more alcohol throughout the night. Hughes et al. (2011) found that males across four European cities intended to consume more alcohol over the rest of the night than females, and $11 \%$ of their 838-participant sample reported having used, or intended to use, illicit drugs. Further, Reed et al. (2011) found that U.S. participants interviewed entering bars later in the evening intended to get drunker than those entering earlier.

Australian surveys indicate that $37 \%$ of adults drink with the intention of getting drunk-51\% of $18-24$ year olds and

Correspondence: Ashlee Curtis, Ph.D., School of Psychology, Faculty of Health, Deakin University, Locked Bag 20001, Geelong, VIC, 3220. Telephone: (03) 5227 8052. E-mail: Ashlee.curtis@deakin.edu.au

Financial support: The current study was funded by a grant from the National Drug Law Enforcement Research Fund.

Declaration of interest: Peter Miller receives funding from Australian Research Council and Australian National Health and Medical Research Council, grants from NSW Government, National Drug Law Enforcement Research Fund, Foundation for Alcohol Research and Education, Cancer Council Victoria, Queensland government and Australian Drug Foundation, travel and related costs from Australasian Drug Strategy Conference. He has acted as a paid expert witness on behalf of a licensed venue and a security firm.

Keywords: alcohol; alcohol-related harm; intention; illicit drugs; nightlife 
61\% of 25-34 year olds (Foundation for Alcohol Research and Education [FARE], 2016), with many of these drinkers expecting, and experiencing, positive short-term outcomes (e.g., feeling happy or relaxed). However, approximately one third reported experiencing more negative feelings (e.g., more tired, regretful, or sad) than they had expected as a result of drinking to get drunk. Alcohol intoxication is also linked to increased likelihood of other drug use, such as alcohol mixed with energy drinks (AmED) or illicit drugs. For example, 8\% of 16-24 year olds in Victoria, Australia, reported first trying illicit drugs because they were under the influence of alcohol (Victorian Drug and Alcohol Prevention Council, 2010). Similarly, crosssectional self-report studies have indicated that use of AmED is associated with increased alcohol consumption, intoxication, and negative alcohol-related outcomes compared to those who consume alcohol only (Peacock, Pennay, Droste, Bruno, \& Lubman, 2013), and it is strongly linked to prolonged heavy episodic drinking, particularly in nightlife contexts (Droste, Miller, Pennay, Zinkiewicz, \& Lubman, 2016; Droste, Pennay et al., 2016). A number of within-subject trials also indicate that AmED can elicit increased desire for greater alcohol consumption compared to alcohol-only conditions (Marczinski, Fillmore, Maloney, \& Stamates, 2016; McKetin \& Coen, 2014). As such, the exploration of AmED as a covariate of nightlife consumption behavior is warranted.

Community-based interventions that have shown some success in reducing high-risk drinking and alcohol-related injuries have tended to incorporate responsible service of alcohol and increased enforcement of alcohol laws. For example, between 1992 and 1996 a five-year community alcohol trauma prevention trial was implemented in California (Holder et al., 2000). The trial focused on mobilizing the community, encouraging responsible beverage service, reducing underage drinking, increasing enforcement of drink and driving laws, and limiting access to alcohol through zoning. The trial resulted in a $6 \%$ decline in self-reported alcohol consumption per drinking event, a $49 \%$ reduction in self-reported "having too much to drink" per six-month period, a $51 \%$ decrease in selfreported driving when over the legal limit per six-month period, a $10 \%$ decrease in nighttime injury traffic crashes in intervention versus comparison communities, and a $43 \%$ decline in emergency department assault injuries in intervention communities compared to comparison injuries. Other community-based programs, such as the Stockholm Prevents Alcohol and Drug Problems (STAD) project, included a focus on responsible service of alcohol, and resulted in a $29 \%$ reduction in violent crimes (Wallin, Norström, \& Andréasson, 2003), and an increase in refusal of service to drunk patrons (Wallin, Gripenberg, \& Andréasson, 2005). However, the STAD project was implemented at a time when there was very little responsible service of alcohol occurring and police were reactive, and as such, any engagement in these activities would be an improvement on the baseline (Curtis et al., 2017).

Further, interventions that rely on the individual making rational decisions while under the influence of alcohol or drugs (such as education campaigns), or that rely on the licensee(s) and their staff to make subjective judgments regarding level of intoxication, are much less effective in reducing intoxication or alcohol-related harms than population-level interventions such as increases in price (Brennan, Purshouse, Rafia, Taylor, \& Meier, 2009; Gray, Chikritzhs, \& Stockwell, 1999; Matthews, Shepherd, \& Sivarajasingham, 2006) or restricted/reduced trading hours (Chikritzhs, Gray, Lyons, \& Saggers, 2007; Chikritzhs \& Stockwell, 2006; Jones, Kypri, Moffatt, Borzycki, \& Price, 2009; Kypri, Jones, McElduff, \& Barker, 2011; Kypri, McElduff, \& Miller, 2014). Where restrictions on price or trading hours are not introduced (e.g., for political reasons or otherwise), ensuring current interventions that target nightlife patrons are having an impact is vital. As such, developing a better understanding of nightlife patrons and their intentions for the remainder of the night is an important step.

In summary, little is known about the association between in situ consumption intentions (alcohol, energy drinks/AmED, and illicit drugs) and BAC, gender, location, and time of night. This study uses data from a large Australian sample of nightlife patrons to explore these variables within a specific drinking occasion. Understanding the consumption intentions of nightlife patrons will inform effective interventions for preventing and reducing alcohol-related harm in the nighttime economy.

\section{Method}

\section{Setting}

This study formed part of the Patron Offending and Intoxication in Night Time Entertainment Districts (POINTED) study, which investigated nightlife attendees' drinking practices, drug use, and experience of harms (Miller, Pennay, Jenkinson et al., 2013). Data were collected in three metropolitan cities (Sydney, Melbourne, and Perth) and two regional cities (Wollongong and Geelong). Sydney, Melbourne, and Perth were selected as locations for this study given they are capital cities within which approximately $50 \%$ of the Australian population reside. Geelong and Wollongong were chosen given they are large regional cities. The full methodology is published in a research protocol (Miller, Pennay, Jenkinson et al., 2013).

\section{Procedure}

Data collection occurred approximately fortnightly on Friday or Saturday nights during December 2011 to July 2012. Interviews were conducted between 8 p.m. and 5 a.m.; however, due to small numbers between 8-8:59 p.m. and 3-4:59 a.m., only data from 9 p.m.-2:59 a.m. are presented. Interviews were conducted by groups of six or more researchers in busy areas within each city. The interviewers wore clothing that clearly indicated the research institution at which they were based. To ensure the sample was systematic and random, every third person within the relevant nighttime entertainment precincts was 
asked to participate, regardless of their gender or nationality. Interviewers were trained to identify intoxicated persons, and persons who were heavily intoxicated were excluded.

Interviewees received a business card with a website link to the study and contact details for the investigators and ethics committee. Interview responses were collected using mobile devices, and a breathalyzer measured BAC (g/100 $\mathrm{ml})$.

\section{Measures}

The survey utilized for the current study was based on a previous study conducted by the team (Miller, 2012), and underwent four sessions of field pilot testing by senior team members in situ prior to commencement of data collection. All pilot data were removed for data analysis. The study variables included the time and location of interview; participant gender and age; and BAC as measured by a breathalyzer. The study variables also included intentions for the rest of the night, such as whether the participant intended to consume additional alcohol, and if so, how many standard drinks; and if they intended to consume energy drinks, AmEDs, or various illicit drugs, and if so, which drugs.

\section{Analysis}

All analyses were conducted using SPSS 23. Chi-square analyses were conducted using adjusted standardized residuals to determine differences in intentions for the rest of the night between BAC level, gender, location (metropolitan vs. regional), and time of night. $P$ values for post-hoc tests were adjusted using the method outlined in Beasley and Schumacker (1995). Chi-square analyses were chosen given the lack of existing literature describing characteristics of nightlife patrons who intend to consume more alcohol, energy drinks, and illicit drugs throughout the night, and as such the inability to appropriately select reference categories for more complex models, such as a logistic regression. For the purpose of analyses, only those who had consumed alcohol prior to the interview were included. Further, as Perth is a unique city that does not fit into the major metropolitan category with Sydney and Melbourne in terms of population size and density of the nightlife entertainment precinct, or regional category with Geelong and Wollongong, it was excluded from the location analysis.

\section{Results}

A total of 4,203 interviews were analyzed; $59 \%$ of the sample was male, with an average age of $25(S D=6.94$; $29 \% 18-20$ years, $37 \% 21-25$ years, $34 \% 26+$ years).

\section{Intention to consume more alcohol}

Over $70 \%$ intended to consume more alcohol after the interview. This was significantly more likely for males, regional participants, and those with a BAC of over 0.08 $\mathrm{g} / 100 \mathrm{ml}$ (Table 1). On average, participants intended to consume a further 5.89 standard drinks.

Intentions to continue drinking progressively decreased throughout the night until 2-2:59 a.m., when an increase was observed. The proportion who intended to continue drinking was higher at 9-9:59 p.m. (82.3\%) compared to 12 a.m.-1:59 a.m. (59\%). After 2 a.m., the proportion (76.3\%) was similar to the 10-10:59 p.m. cohort (78\%), and those interviewed after 2 a.m. were the most likely to have a BAC over 0.081 (48.5\%).

While $72 \%$ of the overall sample intended to consume more alcohol, $85 \%$ of those with a BAC of $0.08-0.12 \mathrm{~g} / 100$ $\mathrm{ml}$ intended to consume more-on average, a further 6.71 standard drinks. Similarly, $84 \%$ of those with a BAC greater than $0.12 \mathrm{~g} / 100 \mathrm{ml}$ intended to keep drinking an average of 7.29 standard drinks (Table 1). BAC steadily increased as the hours in the current consumption session increased. For instance, the adjusted standardized residuals within the BAC category of greater than $0.12 \mathrm{~g} / 100 \mathrm{ml}$ increased from -4.8 (significantly less than expected) at 0 2 hours into their current consumption session to 8.3 (significantly more than expected) at 8 or more hours into their current consumption session.

\section{Intention to consume energy drinks}

Intention to use energy drinks and AmED was relatively consistent across gender and location. However, intention to use energy drinks and AmED was significantly greater for those with a BAC between $0.05-0.08 \mathrm{~g} / 100 \mathrm{ml}$ as compared to other BAC groups, and also greater between 11 p.m. and 12 a.m. (Table 1).

\section{Intention to use drugs}

Intention to use illicit drugs was consistent across BAC levels, location, and time of night. Males were significantly more likely than females to report intending to consume drugs ( $10 \%$ vs. $4 \%$; Table 1$)$. Cannabis and ecstasy were the most common illicit drugs intended to be consumed (37.6\% and $36.6 \%$, respectively), with those who had a BAC between $0.05-0.08 \mathrm{~g} / 100 \mathrm{ml}$ most likely to report intending to consume these substances. Females were most likely to intend to consume ecstasy, whereas males were most likely to intend to use cannabis.

\section{Discussion}

This study demonstrated that the majority of nightlife patrons intended to engage in risky behavior throughout the rest of the night. This was particularly true for those who had a BAC exceeding $0.08 \mathrm{~g} / 100 \mathrm{ml}$, who reported that they intended to consume on average another seven standard drinks post-interview. Those who were interviewed after 2 a.m. also intended to consume another five standard drinks, and were also the most likely to have a BAC over $0.081 \mathrm{~g} / 100 \mathrm{ml}$. 
Table 1

Differences across BAC level $(\mathrm{g} / 100 \mathrm{ml})$, gender, location, and time of night for intentions for rest of night

\begin{tabular}{|c|c|c|c|c|c|c|c|}
\hline & \multirow{2}{*}{$\begin{array}{c}\text { Sample } \\
N=4,203\end{array}$} & \multicolumn{4}{|c|}{ BAC (g/100 ml) } & \multicolumn{2}{|c|}{ Gender } \\
\hline & & $\begin{array}{l}>0-0.05 \\
n=1,075\end{array}$ & $\begin{array}{c}0.05-0.08 \\
n=701\end{array}$ & $\begin{array}{c}0.08-0.12 \\
n=747\end{array}$ & $\begin{array}{c}0.12+ \\
n=489\end{array}$ & $\begin{array}{c}\text { Male } \\
n=2,425\end{array}$ & $\begin{array}{c}\text { Female } \\
n=1,736\end{array}$ \\
\hline \multicolumn{8}{|l|}{ Alcohol } \\
\hline Intend to consume more alc. & $72.0 \%$ & $76.1 \%$ & $79.3 \%$ & $85.3 \%$ & $84.4 \%$ & $73.8 \%$ & $69.6 \%$ \\
\hline Chi-square & & \multicolumn{4}{|c|}{$\chi^{2}=28.45, d f=3, p=.000, \mathrm{~V}=.09^{* * *}$} & \multicolumn{2}{|c|}{$\chi^{2}=8.22, d f=1, p=.004, \mathrm{~V}=.046^{* *}$} \\
\hline$A S R$ & & $-4.4^{+}$ & -0.9 & 3.8 & 2.3 & $2.9^{+}$ & $-2.9^{+}$ \\
\hline \multirow{2}{*}{ Intended no. of drinks } & $M=5.89$ & $M=5.23$ & $M=6.05$ & $M=6.71$ & $M=7.29$ & $M=6.76$ & $M=4.61$ \\
\hline & $S D=5.64$ & $S D=3.81$ & $S D=4.75$ & $S D=6.83$ & $S D=7.13$ & $S D=6.57$ & $S D=3.53$ \\
\hline \multicolumn{8}{|l|}{ Energy Drinks } \\
\hline Intend to consume EDs & $14.1 \%$ & $13.0 \%$ & $17.1 \%$ & $14.6 \%$ & $13.9 \%$ & $14.8 \%$ & $13.2 \%$ \\
\hline Chi-square & & \multicolumn{4}{|c|}{$\chi^{2}=5.91, d f=3, p=.116 ; \mathrm{V}=.044$} & \multicolumn{2}{|c|}{$\chi^{2}=2.014, d f=1, p=.156, \mathrm{~V}=.022$} \\
\hline$A S R$ & & -1.7 & 2.2 & 0.1 & -0.4 & 1.4 & -1.4 \\
\hline Intend to consume $A m E D^{a}$ & $77.1 \%$ & $80.7 \%$ & $90.8 \%$ & $90.8 \%$ & $89.7 \%$ & $76.3 \%$ & $78.3 \%$ \\
\hline Chi-square & & \multicolumn{4}{|c|}{$\chi^{2}=10.01, d f=3, p=.018, \mathrm{~V}=.058^{*}$} & \multicolumn{2}{|c|}{$\chi^{2}=0.901, d f=1, p=.343, \mathrm{~V}=.015$} \\
\hline$A S R$ & & $-2.7^{+}$ & $2.6^{+}$ & 0.5 & -0.2 & 0.9 & -0.9 \\
\hline \multicolumn{8}{|l|}{ Illicit drugs $^{\mathrm{b}}$} \\
\hline Intend to consume drugs & $7.5 \%$ & $7.7 \%$ & $9.7 \%$ & $9.2 \%$ & $8.4 \%$ & $9.6 \%$ & $4.4 \%$ \\
\hline Chi-square & & \multicolumn{4}{|c|}{$\chi^{2}=2.52 ; d f=3, p=.472, \mathrm{~V}=.029$} & \multicolumn{2}{|c|}{$\chi^{2}=40.77, d f=1, p=.000, \mathrm{~V}=.099^{* * *}$} \\
\hline$A S R$ & & -1.4 & 1.1 & 0.6 & -0.2 & $6.4^{+}$ & $-6.4^{+}$ \\
\hline $\begin{array}{l}\text { Which drugs (\% of those } \\
\text { who intended to consume) }\end{array}$ & & $n=1,075$ & $n=701$ & $n=747$ & $n=489$ & $n=2,425$ & $n=1,736$ \\
\hline Ecstasy & $36.6 \%$ & $31.3 \%$ & $44.1 \%$ & $43.5 \%$ & $14.6 \%$ & $32.9 \%$ & $47.4 \%$ \\
\hline Cocaine & $19.4 \%$ & $12.0 \%$ & $16.2 \%$ & $26.1 \%$ & $26.1 \%$ & $20.1 \%$ & $18.4 \%$ \\
\hline Methamphetamine & $16.9 \%$ & $18.1 \%$ & $16.2 \%$ & $11.6 \%$ & $31.7 \%$ & $15.0 \%$ & $22.4 \%$ \\
\hline Pharmaceutical Stimulants & $1.6 \%$ & $1.2 \%$ & $1.5 \%$ & - & $7.3 \%$ & $1.7 \%$ & $1.3 \%$ \\
\hline Cannabis & $37.6 \%$ & $42.2 \%$ & $42.6 \%$ & $31.9 \%$ & $26.8 \%$ & $41.0 \%$ & $26.3 \%$ \\
\hline$L S D$ & $2.5 \%$ & $2.4 \%$ & $1.5 \%$ & $5.8 \%$ & - & $3.4 \%$ & - \\
\hline Heroin/Opiates & - & - & $1.5 \%$ & - & - & - & $1.3 \%$ \\
\hline Ketamine & - & - & - & - & $2.4 \%$ & - & $1.3 \%$ \\
\hline Benzodiazepines & - & - & - & $1.4 \%$ & - & - & - \\
\hline
\end{tabular}

\begin{tabular}{|c|c|c|c|c|c|c|c|c|}
\hline \multirow{3}{*}{-} & \multicolumn{2}{|c|}{ Location } & \multicolumn{6}{|c|}{ Hour } \\
\hline & Metro & Regional & $\begin{array}{c}\text { 9-9:59 } \\
\text { pm }\end{array}$ & $\begin{array}{c}\text { 10-10:59 } \\
\text { pm }\end{array}$ & $\begin{array}{c}\text { 11-11:59 } \\
\text { pm }\end{array}$ & $\begin{array}{c}\text { 12-12:59 } \\
\text { am }\end{array}$ & $\begin{array}{c}1-1: 59 \\
\text { am }\end{array}$ & $\begin{array}{c}2-2: 59 \\
\text { am }\end{array}$ \\
\hline & $n=2,757$ & $n=997$ & $n=171$ & $n=910$ & $n=1,275$ & $n=1,123$ & $n=638$ & $n=86$ \\
\hline \multicolumn{9}{|l|}{ Alcohol } \\
\hline Intend to consume more alc. & $68.7 \%$ & $80.7 \%$ & $82.3 \%$ & $78.0 \%$ & $74.5 \%$ & $69.6 \%$ & $59.0 \%$ & $76.3 \%$ \\
\hline Chi-square & \multicolumn{2}{|c|}{$\chi^{2}=49.29, d f=1, p=.000, \mathrm{~V}=.118^{* * *}$} & \multicolumn{6}{|c|}{$\chi^{2}=81.57, d f=5, p=.000, \mathrm{~V}=.143^{* * *}$} \\
\hline ASR & $-7^{+}$ & $7^{+}$ & $3.0^{+}$ & $4.4^{+}$ & 2.4 & -2.0 & $-7.7^{+}$ & 0.9 \\
\hline \multirow{2}{*}{ Intended no. of drinks } & $M=6.02$ & $M=5.79$ & $M=5.52$ & $M=6.06$ & $M=6.14$ & $M=5.82$ & $M=5.36$ & $M=5.0$ \\
\hline & $S D=5.79$ & $S D=5.61$ & $S D=4.25$ & $S D=4.86$ & $S D=6.63$ & $S D=5.73$ & $S D=4.80$ & $S D=2.69$ \\
\hline \multicolumn{9}{|l|}{ Energy Drinks } \\
\hline Intend to consume EDs & $13.6 \%$ & $14.2 \%$ & $5.8 \%$ & $15.5 \%$ & $16.5 \%$ & $13.4 \%$ & $9.9 \%$ & $20.9 \%$ \\
\hline Chi-square & \multicolumn{2}{|c|}{$\chi^{2}=0.225, d f=1, p=.635, \mathrm{~V}=.008$} & \multicolumn{6}{|c|}{$\chi^{2}=30.44, d f=5, p=.000, \mathrm{~V}=.085^{* * *}$} \\
\hline
\end{tabular}




\begin{tabular}{|c|c|c|c|c|c|c|c|c|}
\hline \multirow{3}{*}{-} & \multicolumn{2}{|c|}{ Location } & \multicolumn{6}{|c|}{ Hour } \\
\hline & Metro & Regional & $\begin{array}{l}\text { 9-9:59 } \\
\text { pm }\end{array}$ & $\begin{array}{c}\text { 10-10:59 } \\
\text { pm }\end{array}$ & $\begin{array}{c}\text { 11-11:59 } \\
\text { pm }\end{array}$ & $\begin{array}{c}\text { 12-12:59 } \\
\text { am }\end{array}$ & $\begin{array}{c}1-1: 59 \\
\text { am }\end{array}$ & $\begin{array}{l}2-2: 59 \\
\text { am }\end{array}$ \\
\hline & $n=2,757$ & $n=997$ & $n=171$ & $n=910$ & $n=1,275$ & $n=1,123$ & $n=638$ & $n=86$ \\
\hline ASR & -0.5 & 0.5 & $-3.2^{+}$ & 1.3 & $3.0^{+}$ & -0.8 & $-3.4^{+}$ & 1.8 \\
\hline Intend to consume $A m E D^{a}$ & $74.2 \%$ & $83.8 \%$ & $80.0 \%$ & $76.6 \%$ & $82.0 \%$ & $71.5 \%$ & $73.0 \%$ & $83.3 \%$ \\
\hline Chi-square & \multicolumn{2}{|c|}{$\chi^{2}=2.548, d f=1, p=.110, \mathrm{~V}=.026$} & \multicolumn{6}{|c|}{$\chi^{2}=31.68, d f=5, p=.000, \mathrm{~V}=.087^{* * *}$} \\
\hline$A S R$ & -1.6 & 1.6 & $-2.7^{+}$ & 1.1 & $3.7^{+}$ & -1.6 & $-3.2^{+}$ & 2.0 \\
\hline \multicolumn{9}{|l|}{ Illicit drugs ${ }^{\mathrm{b}}$} \\
\hline Intend to consume drugs & $7.8 \%$ & $7.2 \%$ & $3.5 \%$ & $7.3 \%$ & $8.6 \%$ & $6.8 \%$ & $7.8 \%$ & $7.0 \%$ \\
\hline Chi-square & \multicolumn{2}{|c|}{$\chi^{2}=0.38, d f=1, p=.579, \mathrm{~V}=.010$} & \multicolumn{6}{|c|}{$\chi^{2}=7.37, d f=5, p=.194, \mathrm{~V}=.042$} \\
\hline$A S R$ & 0.6 & -0.6 & -2 & -0.3 & 1.9 & -1 & 0.4 & -0.2 \\
\hline $\begin{array}{l}\text { Which drugs (\% of those } \\
\text { who intended to consume) }\end{array}$ & $n=2,757$ & $n=997$ & $n=171$ & $n=910$ & $n=1,275$ & $n=1,123$ & $n=638$ & $n=86$ \\
\hline Ecstasy & $39.4 \%$ & $37.5 \%$ & $50.0 \%$ & $33.3 \%$ & $40.0 \%$ & $31.6 \%$ & $36.0 \%$ & $66.7 \%$ \\
\hline Cocaine & $17.6 \%$ & $23.6 \%$ & $16.7 \%$ & $28.8 \%$ & $16.4 \%$ & $14.5 \%$ & $22.0 \%$ & $16.7 \%$ \\
\hline Methamphetamine & $20.4 \%$ & $9.7 \%$ & - & $15.2 \%$ & $15.5 \%$ & $25.0 \%$ & $10.0 \%$ & $33.3 \%$ \\
\hline Pharmaceutical Stimulants & - & $2.8 \%$ & - & $3.0 \%$ & - & $1.3 \%$ & $2.0 \%$ & - \\
\hline Cannabis & $38.4 \%$ & $27.8 \%$ & $33.3 \%$ & $33.3 \%$ & $31.8 \%$ & $46.1 \%$ & $46.0 \%$ & $16.7 \%$ \\
\hline$L S D$ & $2.3 \%$ & $4.2 \%$ & - & $3.0 \%$ & $3.6 \%$ & - & $4.0 \%$ & - \\
\hline Heroin/Opiates & - & $1.4 \%$ & - & - & - & - & $2.0 \%$ & - \\
\hline Ketamine & - & - & - & - & - & - & - & - \\
\hline Benzodiazepines & - & - & - & - & - & - & $2.0 \%$ & - \\
\hline
\end{tabular}

Notes:

V: Cramer's V; ASR: Adjusted Standardized Residual; EDs: Energy Drinks; AmEDs: Alcohol mixed with Energy Drinks

${ }^{\mathrm{a}}$ Of those who intend to consume energy drinks; ${ }^{\mathrm{b}}$ Drugs reported by fewer than $1 \%$ of participants have not been reported here.

Sig at $0.05^{*}, 0.01^{* *}$, and $0.001^{* * *}$

${ }^{+}$Significant residuals

$\wedge$ Perth excluded due to lack of comparability with Sydney and Melbourne.

Intention to consume more alcohol was not stable over the night, with the proportion of those intending to consume more alcohol decreasing until 2 a.m., at which point the proportion increased to levels comparable to earlier in the evening. This may indicate that those participants interviewed in nighttime entertainment precincts between 2 a.m. and 2:59 a.m. are a distinct group of drinkers, but may also be explained by their high levels of intoxication consistent with findings from Bellis et al. (2010).

Consistent with evidence that Australians commonly drink to get drunk (FARE, 2016), those with BAC levels already associated with visible intoxication (Sayette, Martin, \& Perrott, 2001) intended to continue drinking considerable quantities. This is concerning, given the mean intended quantity was almost always above the Australian guidelines of consuming no more than four standard drinks in one occasion to reduce risk of alcohol-related injury (National Health and Medical Research Council, 2009). Similarly, the intention to also use other drugs suggests a motivation to increase levels of intoxication. However, intentions to use stimulants, such as energy drinks, may indicate a need for a "pick me up" later in the night to continue consuming alcohol. Further research investigating the motivations behind these intentions is needed.
Given recent findings regarding drinking-to-get-drunk expectations (FARE, 2016) and how they vary by gender, age, and location, it is important to determine what people expect following the consumption of additional alcohol and other drugs over the remainder of the night. If such expectations are supported, prevention efforts should focus on education regarding expectations versus reality in terms of intoxication-driven consumption.

The current findings also have important implications for nightlife safety strategies, given intoxicated patrons intended to consume more alcohol, energy drinks, AmEDs, and illicit drugs, all of which are associated with increased likelihood of experiencing alcohol-related harm or an aggressive incident (Miller et al., 2015; Miller, Pennay, Droste et al., 2013). Our findings reinforce the importance of responsible service of alcohol within the nightlife, as the intention to consume more alcohol in these areas can be addressed with appropriate implementation and enforcement of such policies in licensed venues, which is in line with findings from the community-based interventions in California and Stockholm (Holder et al., 2000; Wallin et al., 2005; Wallin et al., 2003), and with recommendations by Bellis et al. (2010). Most importantly, and in line with 
recommendations by Hughes et al. (2011), interventions that have been successful at reducing population-level consumption of alcohol, such as increased price and restricted/reduced trading hours, should be implemented, given these would likely be most effective at increasing safety in the nightlife context.

\section{Limitations}

Though intention is the greatest predictor of behavior (Armitage \& Conner, 2001), this study did not assess whether reported intentions were eventually enacted. Future research should follow up on participants to assess eventual behavior.

\section{Conclusions}

The current study demonstrates that a substantial number of patrons who are already intoxicated in the early hours of the morning are intending to engage in further risky behaviors. Interventions focusing on reducing the opportunity for this risky planned consumption, such as increases in alcohol price, restricted/reduced trading hours, and enforcement of responsible alcohol service, are indicated.

\section{Acknowledgments}

Tina Lam is funded by an Early Career Research Fellowship from the Western Australian Health Promotion Foundation (24106). The National Drug Research Institute at Curtin University is supported by funding from the Australian Government under the Substance Misuse Prevention and Service Improvement Grants Fund.

\section{References}

Armitage, C. J., \& Conner, M. (2001). Efficacy of the theory of planned behaviour: A meta-analytic review. British Journal of Social Psychology, 40, 471-499.

Beasley, T. M., \& Schumacker, R. E. (1995). Multiple regression approach to analyzing contingency tables: Post hoc and planned comparison procedures. The Journal of Experimental Education, 64(1), 79-93.

Bellis, M. A., Hughes, K., Quigg, Z., Morleo, M., Jarman, I., \& Lisboa, P. (2010). Cross-sectional measures and modelled estimates of blood alcohol levels in UK nightlife and their relationships with drinking behaviours and observed signs of inebriation. Substance Abuse, Treatment, Prevention, and Policy, 5(5), 1-23.

Brennan, A., Purshouse, R., Rafia, R., Taylor, K., \& Meier, P. (2009). Independent Review of the Effects of Alcohol Pricing and Promotion: Part B. Results from the Sheffield Alcohol Policy Model. Retrieved from Sheffield: https://www.sheffield.ac.uk/polopoly_fs/ 1.95621!/file/PartB.pdf

Chikritzhs, T., Gray, D., Lyons, Z., \& Saggers, S. (2007). Restrictions on the sale and supply of alcohol: Evidence and outcomes. Retrieved from Perth, WA:
http://ndri.curtin.edu.au/local/docs/pdf/publications/R 207.pdf

Chikritzhs, T., \& Stockwell, T. (2006). The impact of later trading hours for hotels on levels of impaired driver road crashes and driver breath alcohol levels. Addiction, 101, 1254-1264.

Curtis, A., Coomber, K., Droste, N., Hyder, S., Palmer, D., \& Miller, P. G. (2017). Effectiveness of communitybased interventions for reducing alcohol-related harm in two metropolitan and two regional sites in Victoria, Australia. Drug and Alcohol Review, 36(3), 359-368.

Droste, N., Miller, P., Pennay, A., Zinkiewicz, L., \& Lubman, D. I. (2016). Environmental contexts of combined alcohol and energy drink use: Associations with intoxication in licensed venues. International Journal Of Drug Policy, 36, 58-66.

Droste, N., Pennay, A. E., Lubman, D. I., Zinkiewicz, L., Peacock, A., \& Miller, P. (2016). The right place at the right time: The social contexts of combined alcohol and energy drink use. Drugs: Education, Prevention and Policy, 23(6), 445-456.

Foundation for Alcohol Research and Education. (2016). Annual alcohol poll: Attitudes and behaviours. Retrieved from http://fare.org.au/wpcontent/uploads/research/FARE-ANNUALALCOHOL-POLL-2016-REPORT-FINAL.pdf

Gray, D., Chikritzhs, T., \& Stockwell, T. (1999). The Northern Territory's cask wine levy: Health and taxation policy implications. Australian and New Zealand Journal of Public Health, 23(6), 651-653.

Holder, H. D., Gruenewald, P. J., Ponicki, W. R., Treno, A. J., Grube, J. W., Saltz, R. F., . . . Roeper, P. (2000). Effect of community-based interventions on high-risk drinking and alcohol-related injuries. JAMA, 284(18), 2341-2347.

Hughes, K., Quigg, Z., Bellis, M. A., van Hasselt, N., Calafat, A., Kosir, M., . . . Voorham, L. (2011). Drinking behaviours and blood alcohol concentration in four European drinking environments: A crosssectional study. BMC Public Health, 11, 918.

Jones, C., Kypri, K., Moffatt, S., Borzycki, C., \& Price, B. (2009). The impact of restricted alcohol availability on alcohol-related violence in Newcastle. Retrieved from Newcastle: http://www.bocsar.nsw.gov.au/ Documents/CJB/cjb137.pdf

Kypri, K., Jones, C., McElduff, P., \& Barker, D. (2011). Effects of restricting pub closing times on night-time assaults in an Australian city. Addiction, 106(2), 303310.

Kypri, K., McElduff, P., \& Miller, P. (2014). Restrictions in pub closing times and lockouts in Newcastle, Australia five years on. Drug and Alcohol Review, 33(3), 323-326.

Marczinski, C. A., Fillmore, M. T., Maloney, S. F., \& Stamates, A. L. (2016). Faster self-paced rate of drinking for alcohol mixed with energy drinks versus alcohol alone. Psychology of Addictive Behaviors, 31(2), 154-161.

Martens, M. P., Rocha, T. L., Martin, J. L., \& Serrao, H. F. (2008). Drinking motives and college students: Further examination of a four-factor model. Journal of Counseling Psychology, 55(2), 289-295. 
Matthews, K., Shepherd, J., \& Sivarajasingham, V. (2006). Violence-related injury and the price of beer in England and Wales. Applied Economics, 38(6), 661670.

McKetin, R., \& Coen, A. (2014). The effect of energy drinks on the urge to drink alcohol in young adults. Alcoholism: Clinical and Experimental Research, 38(8), 2279-2285.

Measham, F. (2006). The new policy mix: Alcohol, harm minimisation, and determined drunkenness in contemporary society. International Journal of Drug Policy, 17, 258-268.

Miller, P., Droste, N., Martino, F., Palmer, D., Tindall, J., Gillham, K., \& Wiggers, J. (2015). Illicit drug use and experience of harm in the night-time economy. Journal of Substance Use, 20(4), 274-281.

Miller, P., Pennay, A., Jenkinson, R., Droste, N., Chikritzhs, T., Tomsen, S., . . . Lubman, D. (2013). Patron Offending and Intoxication in Night Time Entertainment Districts (POINTED): A study protocol. International Journal of Alcohol and Drug Research, 2(1), 69-76.

Miller, P., Pennay, A., Droste, N., Jenkinson, R., Chikritzhs, T., Tomsen, S., . . Lubman, D. I. (2013).

Patron Offending and Intoxication in Night Time Entertainment Districts (POINTED): Final Report. Retrieved from Geelong, Australia: http://www.ndlerf.gov.au/sites/default/files/publicatio n-documents/monographs/monograph-46.pdf

Miller, P., Tindall, J., Sonderlund, A., Groombridge, D., Lecathelinais, C., Gillham, K., . . . Wiggers, J. (2012). Dealing with Alcohol and the Night-Time Economy (DANTE): Final Report. Retrieved from Geelong, Victoria:

http://www.ndlerf.gov.au/sites/default/files/publicatio n-documents/monographs/monograph43.pdf

National Health and Medical Research Council. (2009). Australian Guidelines to Reduce Health Risks from Drinking Alcohol. Retrieved from https://www.nhmrc.gov.au/_files_nhmrc/publications/ attachments/ds10-alcohol.pdf

Peacock, A., Pennay, A., Droste, N., Bruno, R., \& Lubman, D. (2013). "High" risk? A systematic review of the acute outcomes of mixing alcohol with energy drinks. Addiction, 109(10), 1612-1633.

Reed, M. B., Clapp, J. D., Weber, M., Trim, R., Lange, J., \& Shillington, A. M. (2011). Predictors of partying prior to bar attendance and subsequent BrAC. Addictive Behaviors, 36(12), 1341-1343.

Robertson, K., Aitken, R., \& Watkins, L. (2014). Public policy and personal preference: A disconnect between beliefs regarding responsible drinking and the motivation to get drunk. Public Health, 128(11), 1030-1032.

Sayette, M. A., Martin, C. S., \& Perrott, M. A. (2001). Effects of assessment frequency on subjective intoxication ratings after alcohol consumption. Alcoholism: Clinical and Experimental Research, 25(6), 844-846.

Victorian Drug and Alcohol Prevention Council. (2010). Victorian Youth Alcohol and Drug Survey. Retrieved from http://s3.amazonaws.com/zanran_storage/www.health. vic.gov.au/ContentPages/111167689.pdf

Wallin, E., Gripenberg, J., \& Andréasson, S. (2005). Overserving at licensed premises in Stockholm: Effects of a community action program. Journal of Studies on Alcohol, 66(6), 806-814.

Wallin, E., Norström, T., \& Andréasson, S. (2003). Alcohol prevention targeting licensed premises: A study of effects on violence. Journal of Studies on Alcohol, 64(2), 270-277. 